\title{
Diferentes olhares sobre a infância e a criança
}

Raquel Dilly Konrath ${ }^{1}$

\section{Resumo}

Este artigo tem como objetivo trazer algumas reflexões sobre a construção social da infância e a sua relação com outros fatores e contrutos sociais e culturais. Procura apresentar a história da infância e da criança sob diferentes perspectivas e visões, considerando o contexto histórico e cultural construído e produzido dentro de um sistema de significado próprio e não mais universal como o ainda concebido por muitos. Traz como essencial o olhar e o mundo da própria criança em diferentes culturas como fundamentais para a compreensão da infância e da sua construção social.

Palavras-chave: História. Infância. Criança. Cultura. Diferentes olhares.

\begin{abstract}
This article aims at bringing up some reflections on the childhood social construction and its relationship with other factors as well as social and cultural constructions. It will also try to present the History of the Childhood about different perspectives and views, considering the historical and cultural context, which was built and produced in their own meaningful system and not in a universal one as it is still conceived by many people. It emphasizes the views and the child's world itself as something essential in different cultures and fundamental for the understanding of the childhood and its social construction.
\end{abstract}

Keywords: History. Childhood. Child. Culture. Different views.

\section{Introdução}

Lemos o mundo como um texto, e tais leituras são, pela lógica, infinitas (JENKINS, 2013, p. 28).

Olhar e falar sobre a infância e sobre a criança nos provoca a fazer uma reflexão anterior: De que lugar, posição, perspectiva estou me referindo? De que infância ou de que infâncias estamos falando? Referimo-nos à de qualquer criança? É possível falar de uma infância, como se houvesse apenas uma forma de ser criança? Essas e outras questões nos fazem pensar sobre como essas ideias e conceitos são construídos.

\footnotetext{
${ }_{1}^{1}$ Pedagoga. Doutoranda em Processos e Manifestações Culturais pela Feevale (NH). Professora no Instituto Superior de Educação de Ivoti e Feevale (ISEI).raqueldilly@terra.com.br
} 
Jenkins (2013) provoca-nos ao trazer que lemos o mundo por meio do texto, ou seja, de diferentes textos. Isso nos leva a pensar que este(s) texto(s) pode(m) mudar de acordo com os seus autores, que, ao traduzirem a sua visão de mundo, transmitem-nos os seus valores, suas perspectivas, crenças e posição dentro de um contexto maior.

A história é um discurso em constante transformação construído pelos historiadores e que da existência do passado não se deduz uma interpretação única: mude o olhar, desloque a perspectiva, e surgirão novas interpretações (JENKINS, 2013, p. 35).

A partir da perspectiva do autor, a visão de infância e de criança que hoje conhecemos por meio de diferentes histórias são discursos construídos e significados a partir do olhar e da interpretação de quem os produziu. Portanto, não há uma visão única sobre a infância e a criança. Temos diferentes olhares que se constroem e se deslocam conforme a quem se destinam. São visões construídas a partir de fatos do passado, mas interpretados dentro de diferentes sistemas de significados, que mudam conforme o grupo a que pertencem e a quem se destinam. Nesse sentido, podemos dizer que, para compreender as diferentes visões que já se construíram sobre a infância e a criança, é também necessário olhar e enxergar o porquê dessas visões serem construídas assim e não de outras formas.

Cada visão se constrói a partir de uma narrativa que se materializa a partir de um modo de pensar e de ver de um determinado grupo, num determinado tempo, e que opera num determinado discurso de intenções e ações. Por isso, para olhar e pensar sobre a infância e a criança, hoje, é necessário olhar e ler os diferentes textos e discursos. Cada um traz a sua interpretação, intenção e visão, que construiu e produziu diferentes histórias de um passado que não nos é mais possível viver, apenas ler e (re)ler, mas que continua influenciando o nosso presente e acabará interferindo significativamente na nossa condução futura.

\section{Olhares necessários para construir histórias}

A história é ordenada culturalmente de diferentes modos nas diferentes sociedades, de acordo com os esquemas de significação das coisas. O contrário também é verdadeiro: esquemas culturais são ordenados historicamente porque, em maior ou menor grau, os significados são reavaliados quando realizados na prática (SAHLINS, 2011, p. 7).

Dois olhares, ao se apresentarem como contraditórios podem, de alguma forma, ajudar-nos a enxergar as diferentes possibilidades de se construir história. Ao mesmo tempo em que as sociedades organizam as suas ações dentro de um sistema de significados já construídos conforme cada época, lugar e tempo, as pessoas, por meio de suas ações e intervenções, também criam, produzem, reconstroem e mudam significados. Isso quer dizer que também podemos alterar a cultura por meio da ação, ou, ainda, que a história, ao mesmo tempo em que é reproduzida na ação, por ela também é modificada e reconstruída. Através dessa lente, podemos dizer que so- 
mos, portanto, seres reprodutores, produtores e reconstrutores de cultura. E ao nos assumirmos como seres em permanente construção e reconstrução, necessitamos também focar o nosso olhar em nossos diferentes saberes e fazeres.

Ao direcionarmos a nossa visão para esses diferentes olhares de construir história, deparamo-nos com diferentes culturas que podem ser reproduzidas, alteradas e modicadas por pessoas tomadas de diferentes sentidos e significados. Nesse sentido, não teríamos mais como sustentar um único olhar sobre a construção da história da infância e da criança. A historicidade diferencia-se, uma vez que existem diferentes culturas, ou seja, histórias de e para os grupos em questão.

Essa ideia ainda pode ser compreendida como uma nova forma de se olhar para o passado e para a história. Segundo Jenkins (2013), o termo passado traduz os acontecimentos e fatos que já passaram, e que a história seria o que fazemos com esse passado, como o marcamos, definimos e construímos a partir do nosso sistema de significados. Assim, não teríamos somente uma história do passado, mas, sim, muitas histórias, pois aquela visão linear, inquestionável, olhada e contada a partir de uma mesma perspectiva, ou essencialmente uma narrativa dos acontecimentos, é substituída e reconhecida como sendo uma construção cultural, sujeita a variações, tanto no tempo quanto no espaço (BURKE, 1992).

Segundo Burke (1992, p. 2), essa nova visão sobre a história traduz a ideia de que a " [...] realidade é social ou culturalmente construída através de uma estrutura de convenções, esquemas e estereótipos, num entrelaçamento que varia de uma cultura pra outra". Nessa visão, não teríamos mais uma história objetiva, mas diferentes e variadas histórias subjetivadas dentro de um sistema de sentidos e significados, percebidos e interpretados sob diferentes pontos de vista, deslocando o foco do que era considerado central e o que era periférico na história, a partir apenas de uma perspectiva de olhar.

A partir dessa perspectiva, Jenkins (2013, p. 49-50) nos traz que a história é "[...] inevitavelmente interpretativa e posicionada", pois traduz uma forma de pensar e ver o mundo. Dessa forma, não existiriam duas histórias iguais, duas leituras e visões idênticas, tampouco interpretações iguais. Isso também nos levaria a considerar que, da mesma forma, não seria possível dizer que os autores teriam como "impingir suas intenções/interpretações ao leitor", assim como os leitores também não teriam como "discernir por completo tudo que os autores pretendem", e que, assim, cada leitura é um escrito diferente, ou seja, qualquer texto, num outro contexto, tem sentidos e significados diferentes. Segundo o referido autor, essa maneira de ver a história é positiva, pois nos leva a enxergar os acontecimentos e os fatos a partir de diferentes perspectivas e possibilidades, concebendo-a não como algo a ser descoberto e desvelado, mas, sim, construído, e que, assim, também podemos produzir história. A partir dessas diferentes perspectivas de se ver a história hoje, poderíamos enxergá-la como uma construção que se dá a partir de diferentes releituras do passado e interpretações do presente, buscando possíveis sentidos e significados dentro de diferentes sistemas, ainda que: 
Construímos uma trama e uma narrativa do passado a partir das fontes existentes, dos recursos metodológicos escolhidos e de um olhar, dentre vários outros possíveis, marcado por nossa atualidade, vale dizer, por nossa inserção cultural e social, enfim, por nossa própria subjetividade (RAGO apud JENKINS, 2013, p. 10).

Nessa mesma visão, podemos dizer que a história são os acontecimentos e situações e que depende dos olhos de quem a enxerga, a vive ou a interpreta. No entanto, também se faz necessário olhar e procurar enxergar e compreender como e por que essa história se construiu, com que intenções e ações, procurando, ao interpretar o texto (discurso) do outro, também interpenetrar o seu contexto.

\section{$3 \mathrm{Re}(\mathrm{Ver})$ o passado por meio de diferentes histórias: um olhar retrospectivo sobre a infância e a criança}

A história depende dos olhos e da voz de outrem; vemos por intermédio de um intérprete que se interpõe entre os acontecimentos passados e a leitura que deles fazemos (JENKINS, 2013, p. 32).

Ao expressar a visão de Jenkins sobre a história, queremos (re)ver o passado a partir de algumas interpretações que até hoje predominam e dominam as nossas próprias interpretações dos acontecimentos e fatos que marcaram diferentes tempos e lugares. Assim, o processo historiográfico já construído aparece, entra e apresenta-se no nosso cotidiano por meio de diferentes discursos e interpretações. E esses discursos históricos constroem-se a partir de interesses legítimos, influenciando a interpretação de modo a produzir também consensos e conceitos sobre diferentes tempos, acontecimentos e lugares.

Ao trazer e apresentar alguns conceitos historiográficos que marcaram e produziram consensos e conceitos sobre a criança, e que até hoje ainda influenciam e interferem na nossa forma de pensar, ver e conceber a infância, faz-se necessário compreender como esses conceitos se constroem e se inserem no nosso cotidiano.

Os conceitos historiográficos, na visão de Jenkins (2013, p. 38), são "[...] expressões localizadas e particulares", pois são relatos e discursos interpretados num tempo, num espaço e num grupo social com posição e intenção. Segundo o autor, não poderiam ser apresentados como "alicerces universais", uma vez que não são construções impessoais e completamente objetivas, pois sempre se destinam a alguém, com diferentes significados para diferentes grupos.

No entanto, podemos encontrar vários conceitos que influenciaram e definiram consensos sobre a criança, os quais, ainda hoje, influenciam essa percepção, tornando-se a base dos discursos e interpretações da infância no sistema social e educacional. A partir desse olhar, Jenkins (2013) nos traz que, por meio dos conceitos historiográficos, construímos e criamos também a nossa identidade, pois somos definidos e nos definimos, assumindo intenções, posições e ações. E, nesse sentido, apresentamos algumas dessas referências construídas, mesmo que não definitivas, mas que marcam até hoje a identidade infantil.

Podemos explicar, denominar e dominar o mundo por meio de diferentes teorias, assim como podemos representar de diferentes formas a relação que estabele- 
cemos com a criança. De acordo com Damazio (1994, p. 10), “[...] a teoria é o meio de nós entendermos o mundo e agirmos sobre ele". Assim, é importante também olharmos e procurarmos ler a construção dos diferentes conceitos sobre a criança, sob a ótica de diferentes teorias, pois cada uma delas traz a sua visão sobre o mundo. Existem duas teorias clássicas que explicariam a relação do homem com o mundo em que vive, conhecidas como empirismo e racionalismo.

A partir dessas duas abordagens científicas, constituíram-se e construíram-se novos processos, conceitos e perspectivas, até chegarmos nas muitas teorias modernas, que acabam influenciando até hoje a nossa forma de ver e pensar o mundo, assim como a infância e a criança. De acordo com a primeira abordagem, o empirismo, todo o conhecimento e a aprendizagem seriam decorrência da experiência concreta. Os conhecimentos viriam de fora, por meio de estímulos repetitivos. Dentro dessa perspectiva, olharíamos para a criança como um ser incompleto, dependente intelectualmente, aprendendo tão somente a repetir o que o outro, no caso o adulto, julgasse correto.

Já para a segunda abordagem filosófica, o racionalismo, a compreensão do mundo dá-se por meio da razão. Nessa visão, a criança contém em si formas inatas, que se manifestam pouco a pouco, à medida que a maturação orgânica acontece.

A criança, nessa ótica, é um adulto pré-formado, que traz em si as probabilidades de seu conhecimento intelectual. Ao invés de um resultado do meio, a criança será o resultado de sua própria razão, que já nasce com ela e que precisa ser desenvolvida (DAMAZIO, 1994, p. 13).

Segundo Damazio (1994), seria importante conhecermos e compreendermos essas teorias e visões de percepção do mundo, pois elas explicariam a nossa forma de olhar ainda hoje para a criança: ora como um ser passivo e ingênuo, ora como um adulto, um vir a ser. No entanto, hoje temos várias outras teorias e correntes filosóficas trazendo novos olhares e visões sobre a criança e a sua relação com o mundo, as quais nos servem de referência para explicarmos a nossa forma de enxergar, ler e interpretar a infância.

Dentre as diferentes teorias que hoje embasam as nossas ações e intervenções no contexto educacional, podemos destacar as teorias sociointeracionistas. Nessa visão, concebemos a capacidade de conhecer e apreender o mundo por meio da interação, que se constrói a partir de trocas estabelecidas entre a criança e o seu meio. Conforme a teoria sociointeracionista, as crianças não são vistas como passivas ou meras receptoras e nem como um "vir a ser" que progride por iniciativa própria à medida que a maturação orgânica acontece, pois nega "[...] a predeterminação do sujeito: o sujeito não existe por força da bagagem hereditária, nem por força do meio" (BECKER, 2001, p. 113).

A visão sociointeracionista compreende que as crianças, através do contato com seu próprio corpo, com as coisas do seu ambiente, bem como através da interação com outras crianças e adultos, vão desenvolvendo sua capacidade afetiva, a sensibilidade e autoestima, o raciocínio e a linguagem (FELIPE, 2001, p. 27). 
Assim, o desenvolvimento da criança, em seus diferentes níveis e aspectos, dar-se-ia de forma articulada, simultânea e integrada. Podemos citar diferentes teóricos que apresentam o desenvolvimento infantil na perspectiva sociointeracionista, mesmo que de forma bem distinta. Dentre eles, podemos destacar o biólogo e epistemólogo suíço Jean Piaget (1896-1980), o estudioso russo na área da literatura, história, filosofia e psicologia Lev Semenovich Vygotsky (1896-1934) e o médico francês que desenvolveu vários estudos na área da neurologia Henri Wallon (1879-1962). Apesar de apresentarem diferentes pontos de vista sobre a teoria sociointeracionista, seus estudos ainda têm influenciado de maneira decisiva a condução de propostas de muitas escolas infantis até hoje.

Mesmo que não seja de forma direta e consciente, muitas das nossas visões e ações sobre a criança, hoje, produziram-se a partir de conhecimentos prévios que construímos a partir das influências desses estudiosos e de suas teorias ou de muitas outras referências que poderíamos aqui ainda trazer e apresentar sobre a infância e, sem nos darmos conta, tendem a conduzir e direcionar nossas ações como se fossem certeiras e unívocas, e não como construções históricas e sociais a partir de diferentes formas de se olhar e de se ver o mundo. Dessa forma, esses e outros estudos, assim como o avanço de diferentes áreas do conhecimento associadas ao aumento de produção científica, nos últimos anos, têm contribuído e influenciado nossa forma de olhar e ver a criança, produzindo, dessa forma, também modificações na forma de pensar e agir em relação a elas.

Seria impossível apresentar apenas um retrato sobre a infância e de forma assertiva. Em se tratando de uma interpretação que se constrói dentro de um sistema de significados, dentro de um contexto histórico e atemporal, cada teoria, estudo e perspectiva se construindo e reconstruindo a partir de seus próprios sujeitos históricos, influenciam nossa forma de ver e compreender tanto o mundo, quanto a infância e a criança.

\section{Rompendo o daltonismo}

Se tudo é relativo, para que fazer história? (JENKINS, 2013, p. 50).

Ao sermos provocados pela autora pela desventura do relativismo, quando nos deparamos com diferentes visões e interpretações e com o fato de que não existe uma única forma de sentir e olhar os acontecimentos e fatos, questionamo-nos sobre as diferentes possibilidades que esse novo olhar sobre o passado e a história nos proporciona.

Ao olhar sob este prisma, rompemos com o daltonismo que ainda nos faz olhar para o passado e ver a história como construção imparcial e única verdade, e nos faz enxergar um arco-íris de possibilidades e novas perspectivas de se fazer, construir e produzir novas histórias. Vimos que diferentes teorias foram construídas para tentar explicar a nossa forma de ver e agir perante a infância e a criança, mas que não podem ser consideradas como únicas nem podem ser generalizadas, pois são apenas diferentes formas de se constituir no mundo, instaurando diferentes sentidos e significados. 
Para romper o daltonismo, talvez tenhamos que olhar novamente para essas e outras teorias e referências que já construímos e produzimos sobre a infância e a criança, procurando também questionar as nossas certezas e os nossos impregnados discursos, os quais nos dão tanta segurança e nos conduzem ao mesmo lugar, fazendo-nos pensar e agir da mesma forma. Talvez tenhamos que olhar para trás, (re)ver o passado com um novo olhar, um olhar de (re)descoberta, procurando o que está coberto pelo nosso olhar cristalizado, embasado e viciado nas nossas certezas e crenças, a partir das teorias já pré-concebidas.

Ampliando o olhar para este diferente prisma, damo-nos conta de que a ideia de infância, além de ser formulada de diferentes formas, pode vir a não existir em algumas culturas ou sociedades. Nessa perspectiva, Cohn (2009, p. 21-22) convida-nos a pensar numa "antropologia da criança", numa visão particular e não universal. Na visão de Cohn (2009), a criança, assim como a infância, não pode ser concebida fora do seu contexto cultural. Seria imprescindível entender os fenômenos sociais em seu contexto cultural para poder entender e compreender a criança.

A ideia que até hoje temos sobre a infância é, segundo Ariès (1988), uma construção histórico-social do Ocidente, sendo formulada na Europa, simultaneamente com as mudanças na composição familiar, nas noções de maternidade e paternidade, pela institucionalização das crianças pela educação escolar e pelo seu cotidiano. No entanto, precisamos considerar que essa não foi uma construção linear e universal, mesmo que muitos continuem a enxergando assim. Mesmo que nas sociedades ocidentais ela tenha se construído assim e tenha se modificado a partir dessa produção, não podemos pensar que tenha sido a única.

Kulmann (2011) nos ajuda a compreender essa visão, convidando-nos a olhar os outros fatos sociais, os quais envolvem a demografia infantil, o trabalho feminino, as transformações familiares, as questões religiosas, entre outros. Segundo o autor, ao olharmos para a história da infância e da criança, é necessário também olhar para todos os outros aspectos envolvidos e considerar a estreita relação que se estabelece entre a visão de infância e de criança com os demais fatores sociais e culturais. Além disso, chama-nos a atenção o olhar unidirecional para o desenvolvimento da infância apresentado por Ariès, que favorecia a abordagem e a referência da criança sob uma ótica das classes mais altas, da nobreza e da burguesia, desconsiderando as múltiplas camadas sociais subalternas.

Heywood (2004, p. 45) também nos ajuda a ampliar a visão sobre a história da infância e da criança, ao nos alertar que "[...] diversos historiadores arriscam, sem dúvida, uma afirmação um pouco exagerada sobre a descoberta da infância, numa tentativa de dramatizar a importância de suas conclusões", e que essa tentativa nos limita a pensar em conceitos e períodos gerais e universais. No entanto, afirma que "[...] a história cultural da criança tem seus marcos", mas que também se "[...] move por linhas sinuosas", e que, por isso, faz-se necessário examinar as mudanças de conceito a partir das diferentes formas sob as quais as pessoas pensaram e se relacionaram com as crianças, desde a Idade Média à época contemporânea, em seu próprio contexto de experiência e vivência, e não de forma unívoca e generalizada.

Considerando essas mudanças de conceito, Cohn (2009) nos provoca a olhar 
para a infância e a criança de forma muito particular, pois suas vivências e experiências são diferentes em cada lugar, e, assim, teríamos que entendê-las em seu próprio contexto sociocultural. De acordo com a autora, os conceitos de criança e de infância nos parecem muito naturais, mas nos escondem inúmeras complexidades, uma vez que diferentes culturas lidam de forma diferente com suas crianças. Os direitos da criança não poderiam ser significados e compreendidos fora do contexto em que ela vive. Isso nos leva a inúmeros outros questionamentos e interrogações que, num primeiro momento, podem até parecer inquestionáveis, uma vez que naturalizarmos nossos discursos e enxergarmos os fatos e situações a partir dos nossos valores e crenças.

Ainda temos certa dificuldade em assim compreender e enxergar as diferentes infâncias, mas nos parece uma importante possibilidade de repensarmos nossa forma de olhar e ler o mundo. Quem sabe, se ao menos reconhecermos com legitimidade e respeito as diferenças existentes em nossa sociedade, encontraremos novos sentidos frente aos impasses tão complexos colocados na atualidade.

\section{0 olhar da criança: a importância desse olhar}

Não sobram espaços para a liberdade e a criação da criança se sua fantasia está sob controle (DAMAZIO, 1994, p. 38).

É comum ainda reduzirmos as peculiaridades e individualidades das crianças, bem como suas fantasias e o seu imaginário infantil à nossa visão, construída a partir das nossas concepções, ideais e crenças, como também das nossas próprias aspirações. Temos dificuldade para compreender na prática que a criança é um outro indivíduo, que tem a sua forma peculiar de ver e olhar para o mundo. Olhamos para a criança através da nossa lente já viciada com conceitos pré-concebidos, que se transformam em preconceitos e acostumam os nossos olhos a enxergarem a infância sob o nosso prisma, desconsiderando, muitas vezes, suas potencialidades e necessidades.

Como adultos, queremos que a criança enxergue o mundo, não com um olhar livre e aberto, mas que ela olhe através da nossa lente, da nossa visão construída e já condicionada e viciada pelos nossos próprios desejos, valores, frustrações e neuroses, pelas nossas experiências vividas. Dessa forma, agimos como se a criança fosse uma extensão nossa, dos nossos projetos de vida, e não como se nós fôssemos a extensão da criança que um dia já fomos. Temos a pretensão de educar, modificar e transformar as crianças, por meio de projetos pessoais e currículos educacionais, ao nosso modo de ver e interpretar o mundo, desconsiderando, muitas vezes, a forma própria da criança sentir e perceber, construindo seus próprios sentidos e significados. Controlamos seu tempo, o seu espaço e as suas ações, definindo e escolhendo por ela o que fazer, como fazer, e ainda antecipamos, segundo a nossa visão, por que fazer, com o intuito de produzir uma criança idealizada e desejada.

A criança é um ser que dá sentido ao mundo em que vive fazendo diferentes leituras das tramas sociais. Tem, portanto, no decorrer da vida, não só a possibilidade de aprender como também de contribuir para a constituição de um outro momento histórico (MÜLLER; REDIN, 2007, p. 17). 
Ao olharmos para a criança dessa forma, talvez tenhamos que mudar o nosso foco, nos libertarmos dessa forma unilateral de olhar e vê-la, para enxergarmos novas possibilidades de percebê-la.

Abrir espaços para seus movimentos, permitir sua expressão, estimular seus desejos, curiosidades, dialogar honesta e abertamente com ela, reconhecer sua presença, seus sonhos, sua voz e ajudá-la a descobrir as coisas por seus próprios meios e ritmos. Sem violência, mas com lucidez e clareza. Permitindo que ela construa seus mundos tantos quantos forem necessários. Com tevê, bichos, microcomputadores, duendes ou darks, poemas e guache, música e números, com humor e amor, com trabalho e tesão (DAMAZIO, 1994, p. 38).

Para tanto, é imprescindível ouvir a criança, olhar com a criança e não somente falar e olhar para ela com um olhar adulto cêntrico. Nobre $(2007$, p. 58) provocanos ao trazer que pouco perguntamos ou nos indagamos: "O que a criança tem a dizer sobre si mesma? Como elas entendem o mundo e o seu lugar nele?" Para falar e olhar para a criança, também se faz necessário:

[...] compreender os modos de vida próprios das crianças em diferentes culturas, além da curiosidade em decifrar as estratégias utilizadas por elas para lidar com um mundo próprio das crianças, sem desconectá-lo do mundo dos adultos (VASCONCELLOS, 2007, p. 8)

Considerar e compreender o mundo da própria criança nos faz rever a ideia de que a cultura é simples e ingenuamente transmitida através de diferentes artefatos, como objetos, informações, crenças ou valores, esquecendo-se de que ela mesma é capaz de formular sentidos ao mundo que a rodeia. Rever essa ideia nos traz o desafio de conceber a criança como produtora de cultura, e não como reprodutora, e que, de acordo com essa compreensão, "[...] a diferença entre as crianças e os adultos não é quantitativa, mas qualitativa; a criança não sabe menos, sabe outra coisa" (COHN, 2009, p. 33).

De acordo com Dornelles (2012, p. 80), “[...] a criança carrega consigo uma cultura, concebida simbolicamente na imersão das vivências experimentadas em sua comunidade, da qual fará uso ao longo de sua vida". No entanto, Sarmento (2007, p. 36) nos fala "[...] que as crianças incorporam, interpretam e reconstroem continuamente informações culturais, constituídas por valores, normas sociais, ideias, crenças e representações (que fazem parte) dos artefatos culturais". Isso nos faz pensar que, mesmo a criança estando exposta a diferentes culturas, vai construindo a sua de forma individual, a partir de suas significações, com um modo próprio de pensar.

Ao considerar também o olhar da criança como uma importante possibilidade de produzir, construir e narrar as histórias sobre a infância, reconhecemos que existe uma variedade infindável de possibilidades de se olhar para as histórias produzidas e narradas sobre infância e criança. Não é mais concebível nem possível reconhecer essas histórias como legítimas, sem ouvir e considerar o olhar de uma das partes que também as compõem, ou seja, a própria criança. 


\section{Considerações finais: novos olhares}

Estamos acostumados a nos referir e falar da realidade e do contexto atual como se fossem algo único e compartilhado da mesma forma por todos, sem considerar que os fenômenos se constituem dentro de diferentes contextos e se constroem a partir de diferentes sistemas de significados.

Nessa perspectiva, podemos perceber e reconhecer que temos muitas e diferentes referências produzidas e construídas sobre a criança e a infância, e que cada uma delas se constituiu procurando incorporar sentido e significado dentro de seu contexto social e cultural. Considerá-las como importantes referências para compreender e refletir sobre como elas ainda hoje influenciam na nossa forma de olhar e ver a infância e a criança, faz-se necessário para assumirmos uma postura mais ativa e propositiva frente aos desafios da contemporaneidade. Não para concebê-las como universais e determinantes, naturalizando as nossas ações e intenções, mas para compreendermos que nenhuma história é construída de forma ingênua e inocente, que existem diferentes formas de se olhar e interpretar e que essa diferença não está no olhar, mas nas nossas concepções e intenções.

Considerando a necessidade de novos olhares sobre a infância e a criança, remetemo-nos também a pensar em novas formas de narrar as suas histórias, que poderiam ser compreendidas pela metáfora do caleidoscópio, pois cada história é produzida e construída num grande mosaico, em diferentes contextos, de diferentes formas e com diferentes intenções. Teríamos que deixar de lado a linearidade do olhar, muitas vezes estanque e fechado, de narrar a história para substituí-lo por um olhar "caleidoscópico", considerando novas oportunidades e possibilidades de ler, interpretar, produzir e narrar as histórias sobre as diferentes infâncias.

\section{Referências}

ARIÈS, Philippe. História social da criança e família. 2. ed. Rio de Janeiro: LTC, 1988.

BECKER, Fernando. Educação e construção do conhecimento. Porto Alegre: Artmed, 2001.

BURKE, Peter. A nova história, seu passado, seu futuro. In: BURKE, Peter (Org.). A escrita da história: novas perspectivas. São Paulo: UNESP, 1992.

COHN, Clarice. Antropologia da criança. 2. ed. Rio de janeiro: Jorge Zahar, 2009.

DAMAZIO, Reinaldo Luiz. O que é criança. 3. ed. São Paulo: Brasiliense, 1994.

DORNELLES, Leni Vieira. Artefatos culturais: ciberinfâncias e crianças zappiens. In: DORNELLES, Leni Vieira; BUJES, Maria Isabel Edelweis (Orgs.). Educação e infância na era da informação. Porto Alegre: Mediação, 2012. p. 79-103.

FELIPE, Jane. O Desenvolvimento Infantil na perspectiva sociointeracionista: Piaget, Vygostky, Wallon. In: CRAIDY, Carmem; KAERCHER, Gládis (Orgs.). Educação infantil: pra que te quero? Porto Alegre: Artmed: 2001. p 27-38. 
HEYWOOD, Colin. Uma história da infância. Porto Alegre: Artmed, 2004.

JENKINS Keith. A história repensada. 4. ed. São Paulo: Contexto, 2013.

MÜLLER, Fernanda; REDIN, Marita Martins. Sobre as crianças, a infância e as práticas escolares. In: REDIN, Euclides; MÜLLER, Fernanda; REDIN, Marita Martins (Orgs.). Infâncias: cidades e escolas amigas das crianças. Porto Alegre: Mediação, 2007. p. 11-22.

NOBRE, Domingos Barros. Infância indígena guarani MBYA. In: VASCONCELLOS, Vera Maria Ramos; SARMENTO, Manuel Jacinto (Orgs.). Infância (In)visível. Araraquara: Junqueira \& Marin, 2007. p. 53-80.

SAHLINS, Marshall David. Ilhas de história. Rio de Janeiro: Zahar, 2011.

SARMENTO, Manuel Jacinto. Produzindo pedagogias interculturais na infância. Petrópolis: Vozes 2007.

VASCONCELLOS, Vera Maria Ramos. Infâncias e crianças visíveis. In: VASCONCELLOS, Vera Maria Ramos; SARMENTO, Manuel Jacinto (Orgs.). Infância (In)visível.

Araraquara: Junqueira \& Marin, 2007. p. 7-23. 